\title{
DEPENDENT POPULATION AND SECOND DEMOGRAPHIC DIVIDEND IN NEPAL: A STUDY OF ACTIVE SENIOR CITIZENS
}

\section{Durga Bhusal}

\begin{abstract}
This review paper aims to disseminate a viewpoint on natural ability of senior citizen from the alternative angle of traditional perspective to later life. Second career management is essential job in present day of the $21^{\text {st }}$ century. It reviews the existing evidences on aptitude of later life where physical force in the body is not only the means of production recognizing the participation of senior people to their households, communities, and the development course. Supporting generation of the $21^{\text {st }}$ century is progressively having problematic time due to constricted household economy to achieve their obligation of enhancing elderly member of their family. Nepal Labour Force Survey 2017/18 and Population Monograph of Nepal 2014 are utilized as main data sources along with different empirical studies for the explanation to get the target of the study. The crux of this article-later life can contribute the socio-economic development of nation through silver economy involving to the site of earnings to produce more than they consume -posits the alternative perspective to old age dependency.
\end{abstract}

Keywords: Silver Economy, Second Demographic Dividend, Dependent Population, Economic Activity

\section{INTRODUCTION}

The purpose of this review paper is to deliver a viewpoint on potentiality of senior citizen directed towards second demographic dividend. Elderly in unpaid household works has not been mentioned importantly. In order to fulfil the target of this paper author has attempted to introduce the potential perspective to dependent population for second

1 Mr. Bhusal is a Lecturer, Population Studies Department, Butwal Multiple Campus, Rupandehi, TU. 
demographic dividend in Nepal particularly concentrating on active senior citizens. Aging and old age have different concepts. The process of growing old in any age group is ageing. Internationally- on the basis of World Population Data Sheet 2018- old age starts at the age 65 year. Central Bureau of Statistics (CBS) Nepal (2014) classifies people in the age range 60 years and above as old. It further says that the chronological age of beginning old age is relative to the person and the context, and retirement age is considered as the starting age of getting old. It says again for practical purpose however the chronological age 60 years is considered as the beginning of young old hood. It is difficult to understand that which definition to address elderly population is justifiable. A clear example of contradiction for initial boarder of senior citizens in the study of Dhakal (2012) can be seen that the retirement age from the governmental jobs that 58 years in general administration, 60 years for the health services, 63 years for the judiciary and university services, and 65 years for the Chief Justice and other members of constitutional bodies. However, there is no retirement age for members of political parties, social workers and consultants.

Mason and Lee (2006) argue that strong economic growth for nation and economic support system for senior citizens are two policy challenges developing from the aged society should be sustained. The second demographic dividend from the population of age group 60+ should rely on public transfer system. Accumulation of pension wealth along with continued reliance can be used in income generating activities with the help of effective policies in order to make prosperous society. Population aging provides a powerful incentive for capital accumulation. This article helps to point the effective policy can generate the economic support system for senior citizens who are considered as consume more than they produce.

The book of Bloom, Canning and Sevilla (2002) explore the debate over population change and economic growth among economists and demographers. They continue to disagree about whether population growth (a) restricts, (b) promotes, or (c) is independent of economic growth. Proponents of each view can point to research evidence to support their cases. Authors have also written that the demographic dividend does not occur automatically however sustain economic growth as in East Asian economies can be achieved by giving concentration on policy areas of public health, family planning, education, labor- market, trade, and savings. Exploitation of matured young is the window of opportunity to accelerate the economic growth. Policymakers must plan for the future health care and pension-income needs of this baby-boom generation when 
it ages that concerns with second demographic dividend. The relation between population growth and economic growth is not always positive and this norm of relation helps to develop the awareness in preparation and implementation of policy is the guiding concept can be used in this article.

Scholarly accepted earning capacity embedded into senior citizens can be understood from this coat "The impact of senior citizens on economy and society is described as silver economy" (Ivana and Aleksandar 2017). This study points out silver economy is related to economic activities of $50+$ years population and the estimation of size of the world population age 65 and over by the year 2050 will be the more than $20 \%$ of world population. They add that European Union (EU) countries have recently started to change traditional consideration about elderly persons from fiscal burden to market opportunity. Increasing size of senior citizens in the world shows the similar condition in Nepal too. The concept of silver economy will be the foundation to get rid of the burden from dependent population in some extent is the main theme can be used in my article in showing the probability of second demographic dividend. Burden can be transferred to opportunity if and only if effective policy starts to work.

It seems to keep nominal meaning come from cultural practice about senior citizens and dependency but the understanding was meaningful at the time of life expectancy at birth 40-45 years. Life expectancy at birth in Nepal has reached 70 years that is the ground to modify the older version of dependency and active senior citizens. The issue brain storms that why the value is not similar in definition with the international organizations. Data comparison has been difficult from this dissimilarity. One example: dependency rate for Nepal is calculated on the data of population 60 years and above while internationally it is based on population 65 years and above. Then, should we not think about it on the totally different ground of socio-economic and demographic reality is my concern about the issue. This article is the attempt to gather information relevant to window of opportunity for second demographic dividend. The term 'second' before demographic dividend is for senior citizens in the sense that 'first' is related with working age population where there should be accelerated economic growth. Save Age International and American Association of Retired Persons (AARP) say that "older persons must be recognized as the active agents of societal development in order to achieve truly transformative, inclusive and sustainable development outcomes". I have dug the hidden meaning embedded in the issue of contradiction on dependency and demographic dividend particularly in the case of active senior citizens of 
Nepal. Secondary data from the population monograph of Nepal to analyze the economic situation and population composition, and other research works for the clarification of concept of my claim - active senior citizens are not dependent and they can contribute the nation economically in positive direction - have been used.

\section{CONTEXTUALIZATION OF PROBLEM}

The population in old age are addressed more respectfully senior citizens. These people are considered as economically dependent in the sense they produce less than they consume because they are in the age group of retired life. Actually, senior citizens are full of experience about conduction of life. They can suggest and present the guidelines for newer generation. Physiologically weaker than younger adult does not mean they cannot produce any more. The socio-economic condition during the period of setting old age border line is entirely different today. Senior citizens' longer life on the basis of life expectancy at birth according to Population Reference Bureau (PRB) is one indicator to study about their economic contribution. The value of life expectancy at birth, 70 years for male and 71 for female in Nepal (PRB 2018) is in increasing nature because fertility and mortality are decreasing rapidly. It shows the senior citizens are spending their healthy life. Active senior citizens voluntarily engage in economic activities. Many retired persons are searching the opportunity for their second career development, and practicing as consultants to maintain their capacity and health. For the last two decades, social scientists and demographers all over the world, including Nepal, are trying to explore the dynamics of ageing. The life expectancy at the year 65 is 13 years for male and 15 years for female mentioned in PRB (2018) is the indication of elderly population of Nepal at the age of 65 years has approximately 15 years to live in average. The factual information explained in this paper concerning to mortality rate, life expectancy, economic growth rate, and dependency clarifies the purpose of this article.

Qualitative descriptive research study conducted in 12 districts east and west of Kathmandu valley Jonas (1992) reveals from the answer of 25 elders that some want to die, some are feeling joy and respect, the value of time is meaningless. The study comprises $50-81$ years elders' responses where life expectancy at birth was recorded 43 years. This study shows that elder people in Nepal are not happy and satisfied from the service of government and family or society. Now the health scenario has changed since life expectancy at birth has increased. 


\section{DATA AND METHODS}

The main sources of information have been reviewed in this paper are various empirical studies along with report of Nepal Labour Force Survey (NLFS) 2017/18 which has collected the information of senior citizens engaged in economic activities, and figures of population censuses published in Population Monograph of Nepal 2003 and 2014 to compare the past and present demographic and economic status of senior citizens. Secondary data are analyzed to meet the target of this paper. No any statistical technique is applied to put in this analytical viewpoint. This article sheds the light to answer "How does the active senior citizens engage in the purpose of economic development of the nation?" Can the active senior citizens be understood as the nondependent population group? To investigate the potential economic value of active aging and to reflect the aptitude of senior citizens in Nepal is the main purpose of this review article.

\section{RESULTS AND DISCUSSION}

Bloom, Canning, and Fink (2010) have described the policy implication of the historical guidance on new generation in their article "Implication of population ageing for economic growth". Their one of the conclusions is that 'prospective old age dependency ratio'-the ratio of population having life expectancy less than 15 to the 20 years old population having life expectancy more than 15- differs 'old age dependency ratio'- ratio of population of $60+$ years to the population of $15-59$ years- where perception about senior citizens changes with the help of first kind of dependency ratio. Prospective old age perspective is the alternative vision to respect the increasing life expectancy reflecting long later life span. Having presented the demographic profile, economic contribution of elderly in the context of Nepal has been mentioned in this discussion. Unpaid household work of senior citizens is so important in freeing up from household work the working aged group to involve in labor market. This indirect economic contribution of elderly has not been understood in earning role.

\section{Demographic changing status of Nepal}

National Planning Commission (NPC) presents the decreasing trend of total fertility rate and crude death rate. This study shows the data 2.32 and 6.5 respectively in the period 2010-15 that was 5.62 and 16.9 in the period 1980-85. Life expectancy at birth 69.01 is the result of rapid increase from 48.34 during the 35 years of interval (2017). Latest data from world population data sheet 2018 shows the life expectancy at birth for male 70 years and that for female is more by one. It shows that females live 
longer than males. Senior citizen's issue has become sole concern of world including Nepal.

Senior citizens are generally considered as 'forgotten generation' with various stereotypes- being senile, sick, unattractive, incapable and rigid in one hand and on the other hand international political as well as economic leadership is in grasp of senior citizens. This claim can be justified from a report published by Forbes mentioning top 10 world's powerful people in 2018 where $70 \%$ are senior citizens. Senior Citizen Policy 2001, Nepal aims to enhance the respect and dignity of the elderly in their family, society, and nation. It also determines to improve the potential of the elderly so that they continue to be active and productive in national development and create opportunities to assist them in continuing to be self-reliant. Senior Citizen Act, 2006 to ensure the social, economic and human rights of the elderly citizens. These act and policy agree the existence of elder capability to perform economic activity in Nepal. The traditional concept of old age dependent population at the time of high mortality rate and low life expectancy at birth has become at the stage of meaningful consideration in order to redefine the dependency.

\section{Population size growth and doubling time}

Worldwide increasing trend of senior citizens can be experienced in Nepal. Increasing population growth rate and shortening population doubling time shows senior citizens' population is rapidly increasing.

Table 1: Ageing status (60 years and above) of Nepal

\begin{tabular}{cccc}
\hline Survey year & Population & Growth rate & Doubling time \\
\hline $1952 / 54$ & $4,09,761(5.0)$ & - & - \\
1961 & $4,89,343(5,2)$ & 1.7 & 41 \\
1971 & $6,21,529(5.4)$ & 2.4 & 29 \\
1981 & $8,57,061(5.7)$ & 3.2 & 22 \\
1991 & $10,71,234(5.8)$ & 2.2 & 22 \\
2001 & $15,04,311(6.5)$ & 3.4 & 32 \\
$2011^{*}$ & $21,54,408(8.1)$ & 3.5 & 20 \\
\hline
\end{tabular}

Source: Pantha \& Sharma 2003 and *Singh, 2014

Note: Parenthesis containing figure represents the percentage of total population

Trend of aged population growth rate and population doubling time shown in Table 1 is the 50 years' experience where changed growth rate 
of elderly is more than double from 1.7 to $3.5 \%$, and changed population doubling time is less than half from 41 to 20 years. This is the indication of rapidly growing elderly people.

\section{Share of elderly by single year of age and sex}

Elderly population is divided in three broad age groups. First, young-old having age in the group (60-69) which are mobile and experience little functional limitation, second, old-old in the age group (70-79) have some disabilities that lead to an increasing restriction of the function and can take care of themselves, and third, oldest-old $(80+)$ is frail group with total dependency and need total support. 60-69 is the population age group of active senior citizens. Population of individual year in the group helps to understand the presence of population size whether it is smooth.

Table 2: Percentage population distribution of 60 years and above by sex, 2011, Nepal

\begin{tabular}{ccc|}
\hline Age & $\begin{array}{r}\text { Male cumulative } \\
\text { percent }\end{array}$ & $\begin{array}{c}\text { Female cumulative } \\
\text { percent }\end{array}$ \\
\hline $60+$ & 8.29 & 7.97 \\
$61+$ & 6.87 & 6.57 \\
$62+$ & 6.49 & 6.21 \\
$63+$ & 6.02 & 5.74 \\
$64+$ & 5.71 & 5.41 \\
$65+$ & 5.42 & 5.12 \\
$66+$ & 4.49 & 4.16 \\
$67+$ & 4.22 & 3.90 \\
$68+$ & 3.92 & 3.62 \\
$69+$ & 3.47 & 3.24 \\
$70+$ & 3.27 & 3.09 \\
\hline Total population & 12849041 & 13645463 \\
\hline
\end{tabular}

Source: Adhikari, 2014

Table 2 shows the population size of active senior citizens by sex and single year of age. $5.02 \%$ of male total population is male active senior and $4.88 \%$ of female total population is female active senior. More than 13 lakhs population is in the age group 60-69 which is in the age that they can produce more than they consume because they are under the average life expectancy at birth. 


\section{Working hours of senior citizens}

Senior citizens may have weak physiological structure but it does not mean that they are totally dependent. Those who are in active old age group approximately competitive in work with population of active age group. Leading capability of senior citizens in political sector can be taken as an illustration of their potential. The favorable environment is necessary for the usage of senior citizens' skill, experience, and knowledge. The dependent population indexing active senior citizens is in the stage of consideration in order to change the traditional thought. Activeness of the group can be understood from the report of working hours of old aged population.

Table 3: Hours of works by age and sex, Nepal

\begin{tabular}{cccc}
\hline Age group & Male & Female & Total \\
\hline $55-64$ & 45 & 35 & 42 \\
$65+$ & 35 & 30 & 36 \\
\hline
\end{tabular}

Source: CBS, 2018

Older people are generally understood as service recipient because of their fragile body and experience limited activities however survey data show that $65+$ yrs. Table 3 shows that older people work on more than 36 hours per week. This becomes more than 5 hours per day.

\section{Monthly earning of senior citizens}

Senior citizens can contribute the nation through economic earning. Average earning scenario of senior citizens has seriously developed a question "Is the population which can earn the money more than its consumption level, dependent?" in the field of population management.

Table 4: Average monthly earnings of employees in the main job by broad age group, Nepal

\begin{tabular}{cc}
\hline Age group & Earning rupees \\
\hline Total & 17809 \\
$15-24$ & 14595 \\
$25-39$ & 18158 \\
$40-59$ & 19739 \\
$60+$ & 15967 \\
\hline
\end{tabular}

Source: CBS, 2018 
CBS, (2018) through Nepal Labour Force Survey 2017/18 classifies a person as employed when he/she has worked for at least one hour during the reference week. Table 4 shows that mean monthly earning Rs. 15967 contributed by older people of 60 years and above are more than that earning Rs. 14595 by population of 15-24 age group.

\section{Age dependency and economic dependency ratio}

According to Amadeo 2018, United Nations (UN) calculates the age dependency ratio on the basis of formula Youth 0-14 years plus Seniors 65+ years divided by workers 15-64 years and World Bank calculates an age dependency ratio in the structure of UN but without counting children that $65+$ years population is divided by 15-64 years population. He explains that not all those aged 65+ have stopped working and many of those aged 15-64 are not working for various reasons. Labor force participation rate for each age group can give the accurate dependency estimates as in USA explained by Amadeo where Labor force is divided by civilian non institutionalized population-15 years and above population minus those in prisons, nursing homes \& mental hospitals minus those who are in active duty in armed force. Nepal follows the structure of UN to calculate age dependency taking seniors aged 60 years and above. This dependency ratio calculating idea of Nepal should consider differently in order to clarify the relation of age dependency and economic dependency.

Table 5: Percentage distribution of economically inactive population by reason of aged, 1991-2011, Nepal

\begin{tabular}{cc}
\hline Census year & Population percent \\
\hline 1991 & 10.44 \\
2001 & 7.72 \\
2011 & 6.17 \\
\hline
\end{tabular}

Source: Suwal \& Dahal, 2014

Suwal \& Dahal (2014) mentions that $44.7 \%$ of population having age 10 years and above is economically not active in Nepal. Table 5 shows the decreasing order of inactive population percentage reporting 'inactive due to aged'. This order is the reflection of increasing trend of senior citizens who want to be active.

Economic contribution of active senior citizens is inevitable side because of the refined activity rate of active senior citizens that is more than the contribution of age group 15-19 and 20-24. This is the important part 
of senior citizens that they are not categorized in the group of dependent population. The trend of past 20 years economic activity of senior citizens is given in Table 6 .

Table 6: Refined activity rate by age group 2011, Nepal

\begin{tabular}{ccc}
\hline Census year & $\mathbf{6 0 - 6 4}$ & 65 year and above \\
\hline 1991 & 45.96 & 26.92 \\
2001 & 67.23 & 47.12 \\
2011 & 67.34 & 58.74 \\
\hline
\end{tabular}

Source: Suwal \& Dahal, 2014

The increasing trend of economic activity rate of senior citizens shown in Table 6 indicates the healthy aging of senior citizens. Large number of senior citizens can be seen in economic sector challenging their so-called old age dependency in order to make their own healthy and satisfied life.

Government of Nepal can use the economic contribution of active senior citizens to get demographic dividend. Proper policy for income savings in working age period can motivate active population to secure their old age life. This saved money can be invested to increase economic growth and would be the second demographic dividend.

\section{CONCLUSION}

The economic contribution of active senior citizens who are also called young old can contribute the nation economically too in the amount greater than the contribution of population having age 15-19 and 20-24. The old age dependency ratio comprising all senior citizens should be modified because active seniors can contribute to economic development. This can be justified by calculating dependency ratio on the basis of consumption only can give the clear meaning of actual dependency where it is calculated as consumption of elderly population which is not financed by their own income to the income of the working population which exceeds their own consumption. Active seniors being not dependent in real sense, should be segregated from the traditional saying of old age dependent group.

The demographic dividend hypothesis starts with the assumption that workers, or at least productive workers, are to be found in the "working age' population (15-59 or 15-64) and that economic development relies on raising the country's per capita productivity. Investment of old age earnings, and saving from their economically active life period reflect their prosperity in later life is the effective way of getting second demographic 
dividend from active senior citizens is the concept derived from the study of Vera-Sanso (2013) in this review article. Second career management should be the key concern of Nepal to mitigate probable demographic, socio-economic, and psychological problems in near future.

\section{REFERENCES}

Adhikari, U. P. (2014). Age sex composition. Population Monograph of Nepal. 1, CBS, Kathmandu, Nepal, pp. 39-65.

Amadeo, K. (2018). Dependency ratio \& how it affects you. https://www. thebalance.com.

Bloom, D., Canning, D. \& Sevilla, J. (2002). The demographic dividend: A new perspective on the economic consequences of population change. Population Matters. RAND.

Bloom, D.E., Canning, D., \& Fink, G. (2010). Implications of population ageing for economic growth. Oxford Review of Economic Policy 26(4): 583-612.

CBS (2003). Population Monograph of Nepal. Kathmandu: NPC, Government of Nepal.

CBS. (2014). Population Monograph of Nepal. Kathmandu: NPC, Government of Nepal.

CBS (2018). Nepal Labour Force Survey 2017/18. Kathmandu: NPC, Government of Nepal.

Dhakal, M. R. (2012). Ageing and health in Nepal. Regional Health Forum, 16(1). https://pdfs.semanticscholar.org.

Forbes, (2018). The world's most powerful people. https://www.forbes.com > powerful-people > list

Ivana, B. \& Aleksandar, B. (2017). Silver economy: Demographic change and economic opportunity. Interdisciplinary Management Research 13. Josip Juraj Strossmayer University of Osijek, Faculty of Economics in Osijek Croatia, pp 1005-1020.

Jonas, C.M. (1992). The meaning of being elder in Nepal. Nursing Science Quarterly 5(4): 171-175. doi:org/10.1177/089431849200500409.

Mason, A., \& Lee, R. (2006). Reform and support systems for the elderly in developing countries: Capturing the second demographic dividend. Genus, 62(2): 11-35. http://www.jstor.org/stable/29789308 
Ministry of Women, Children and Social Welfare. (2001). Senior citizen policy. Kathmandu: Government of Nepal.

Ministry of Women, Children and Social Welfare. (2006). Senior citizen act. Kathmandu: Government of Nepal.

NPC (2017). Demographic changes of Nepal: Trends and policy implications. Government of Nepal, Kathmandu.

Pantha, R. and Sharma, B.R. (2003). Population size, growth and distribution. Population Monograph of Nepal. CBS, Kathmandu, Nepal, pp. 37-86.

PRB (2018). World population data sheet. Population Reference Bureau. UN.

Singh, M. L. (2014). Aspects of aging. Population Monograph of Nepal. 2 , CBS, Kathmandu, Nepal, pp. 73-110.

Suwal, R. and Dahal, M.P. (2014). Economically active population: Dimensions and dynamics. Population Monograph of Nepal. 3, CBS, pp. 1-38.

Vera-Sanso, A. (2013). Aging, work and the demographic dividend in South Asia. In J Field, R. Burke and C. Cooper (eds). The SAGE handbook of aging. London: Sage. pp. 170-185. 